\title{
STUDIES ON THE CHARACTERS OF ANTIBIOTIC STREPTOMYCES V. ON TYPES OF S. GRISEUS
}

\author{
BY YoshIRo OKAMI \\ The National Institute of Health of Japan \\ (Received for publication, May 27, 1950)
}

S. griseus is a wellknown species of streptomyces, and its range was first described by Krainsky (1), thereafter by Waksman 1919 (2), and recently in Bergey's Manual of Determinative Bacteriology (1948). At present Waksman's compilation in the above latest book seems to be widely accepted, however the detailed studies of this species which are due to the necessities for streptomycin production indicate that, though the strains producing streptomycin or grisein conform to the descirption of S. griseus in most of all characters, among these strains there are several differences which divide. them into three types. During examining 47 strains of streptomycin-producing $S$. griseus, 5 strains of grisein-producing $S$. griseus and 4 pink-pigment-producing $S$. griseus, the writer found following varieties.

(1) The typic S. griseus,

(2) The pink-pigment producing S. griseus, and

(3) The strains which do not produce yellow pigment when they grow on potato plug.

Moreover, from the point of the antibiotic production there are various varieties such as producing streptomycin, grisein, other antibiotics or none.

The character of producing pink pigment is very stable and noticeable so that it is thought to be an important specific character differentiating the strain as a special type. The streptomycin-producing ability is also thought as an special character indicating a special type. Then the others such as grisein-producing will be the other type.

The effect of actinophages are rather strain specific, however, it seems to be worthy for the differentiating the types. An actinophage does not attack all streptomycinproducing strains. The utilization of sugars seems to be an important point of differentiating types. As described in the previous paper (3) the above typing. is also sustained by experiments of sugar utilization.

\section{EXPERIMENTAL}

56 strains which were isolated by Umezawa and others were examined. Among them 47 strains are streptomycin-producing, 5 strains grisein-producing, and 4 strains pinkpigment-producing. . Streptomycin-producing and grisein-producing strains conform to the description in Bergey's book, except 12 streptomycin-producing strains do not produce yellow pigment, when they grow on potato plugs.

Two kinds of actionophages, the one was isolated from the contamination to the streptomycin-producing strain No. 41 (4) and the another from the contimination to the 
strain No. X-28 at Kyowa Fermentation Industries Co., were examined on their lytic effects on the above strains. On the glucose asparagine agar slant S. griseus was streaked and immediately thereafter one drop of phage solution was put in the bottom and incubated for 4 days at $27^{\circ} \mathrm{C}$. In the case when the growth near the bottom was inhibited, the strain was determined to be sensitive to the phage.

As shown in Table 1, they do not attack grisein-producing and pink-pigment-producing

Table 1." Strain specificity of actinophage.

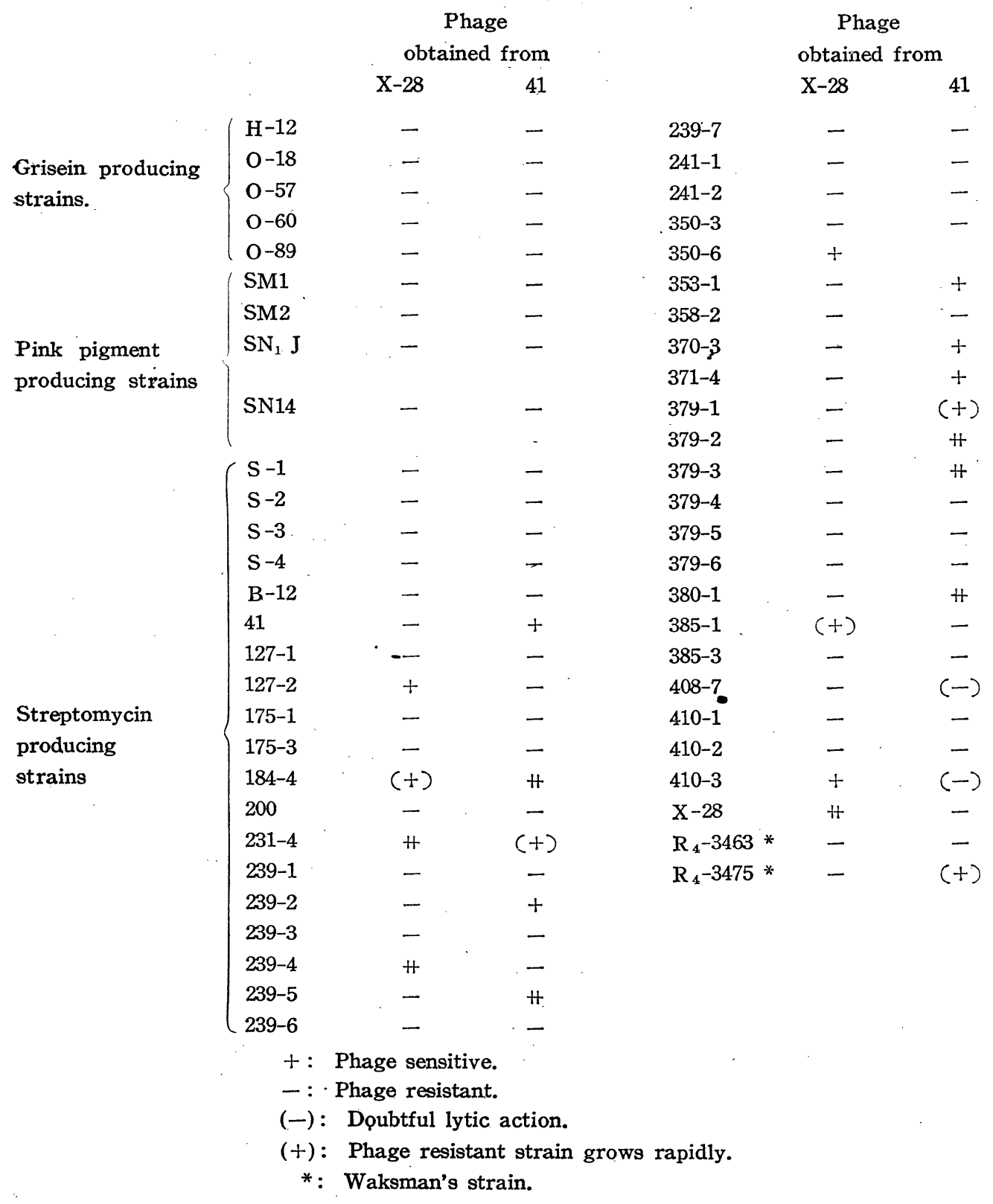

strains, therefore their specificity seems to be important for differentiating types. How- 
ever, the one actinophage does not attack all streptomycin-producing strains. Their effect is strain specific. Moreover, some streptomycin producing strains are sensitive to both phages, but some others are sensitive to only one of them.

The utilization of carbohydrates was examined as the following:

The Czapeck's solution without sugar was sterilized for 20 minutes at $120^{\circ} \mathrm{C}$, and thereafter various carbohydrates were added to $2.0 \%$, and litmus solution was added to the amount necessary for indicating the acid production and sterilized by filtration through Seitz filter, and divided into sterile tubes. Each tube was inoculated with the growth on glucose asparagine agar slant, and incubated for 7 days at $27^{\circ} \mathrm{C}$. Every day the growth, the turbidity and the change of the color were examined. As shown in Table 2, all strains grow in the medium containing xylose and not in that containing

Utilization Table 2 . of carbohydrates

\begin{tabular}{|c|c|c|c|c|c|c|c|c|}
\hline & & Glyceliol & Glucose & Maltose & Raffinose & Rhamnose & Sucrose & Xylose \\
\hline \multirow{6}{*}{ I } & $\mathrm{H}-12$ & + & $H$ & + & - & - & + & + \\
\hline & $0-18$ & + & H & + & - & - & + & + \\
\hline & $0-57$ & + & $H$ & + & - & - & + & + \\
\hline & $0-60$ & 4 & $H$ & + & - & - & + & + \\
\hline & O-89 & + & H & + & - & - & + & + \\
\hline & SM-1 & + & - & - & - & - & - & + \\
\hline \multirow{23}{*}{ II } & SM-2 & + & - & - & - & - & - & + \\
\hline & SN1J. & + & - & - & - & - & - & + \\
\hline & SN14 & + & - & - & - & - & - & + \\
\hline & $S-1$ & - & - & + & - & - & - & + \\
\hline & $\mathrm{S}-2$ & - & - & $(+)$ & - & - & - & + \\
\hline & $S-3$ & - & - & + & - & - & - & + \\
\hline & $S-4$ & - & - & + & - & - & - & + \\
\hline & $\mathrm{B}-12$ & $(+)$ & - & + & - & - & - & + \\
\hline & 41 & - & - & + & - & - & - & + \\
\hline & $127-1$ & - & - & $(+)$ & - & - & - & + \\
\hline & $127-2$ & - & - & $(+)$ & - & - & - & + \\
\hline & $175-1$ & - & - & + & - & - & - & + \\
\hline & $175-3$ & - & - & $t$ & - & - & - & + \\
\hline & $184-4$ & - & - & + & - & - & - & + \\
\hline & 200 & - & - & + & - & - & 1 & + \\
\hline & $231-4$ & - & - . & + & - & - & - & + \\
\hline & 239-1 & - & - & + & - & - & - & + \\
\hline & $239-2$ & - & - & + & - & - & - & + \\
\hline & $239-3$ & - & - & $(+)$ & - & - & - & + \\
\hline & $239-4$ & - & - & $(+)$ & - & - & - & + \\
\hline & $239-5$ & - & - & $(+)$ & - & - & - & + \\
\hline & $239-6$ & - & - & + & - & - & - & + \\
\hline & $239-7$ & - & - & + & - & - & - & + \\
\hline \multirow{2}{*}{ III } & $241-1$ & - & - & $(t)$ & - & - & - & + \\
\hline & $241-2$ & $(+)$ & - & - & - & - & - & + \\
\hline
\end{tabular}


Designation :

+ : Growth and positive utilization.

-: No growth, no utilization.

$(+)$ : Poor growth.

I: Grisein producing strains.

II : Pink pigment producing strains.

III : Streptomycin producing strains.

raffinose or rhamnose. This character of carbohydrate utilization seems to be an important specific character of S. griseus. The utilizations of glucose, glycerol, sucrose and maltose are important for differentiating the types among S. griseus. Streptomycinproducing strains grow in the medium containing maltose, but not in that containing glucose, glycerol or sucrose. Grisein-producing strains grow in the medium containing each of all above sugars. Pink-pigment-producing strains grow only in the case of glycerol, but not in other cases.

As indicated in the summarized Table 3, the utilization of glucose, glycerol, sucrose or maltose is one of the most important characters for typing strains of $S$. griseus. However, on the point of utilization of glucose, Pridham's paper (5) should be noticed. He found $S$. griseus grows in the glucose medium, when ammonium sulfate is present as the nitrogen source. It suggests that the utilization of the sugar depends upon nitrogen sources. Therefore the writer traced the Pridham's experiment and could confirm his results. When the medium contained, $0.1 \% \mathrm{~K}_{2} \mathrm{HPO}_{4}, 0.05 \% \mathrm{MgSO}_{4}, 0.05 \% \mathrm{KCl}, 0.001 \%$ $\mathrm{FeSO}_{4}, 0.2 \%\left(\mathrm{NH}_{4}\right)_{2} \mathrm{SO}_{4}$ and $2.0 \%$ glucose, then streptomycin-producing and pink-pigmentproducing strains grew in the medium. Therefore, for differentiating the types, Czapeck's solution which contains sodium nitrate as the nitrogen source should be used. Also 
Table 3.

\begin{tabular}{|c|c|c|}
\hline \multirow{3}{*}{ S. griseus. } & Raffinose & - \\
\hline & Xylose & + \\
\hline & Rhamnose & - \\
\hline
\end{tabular}

\begin{tabular}{ll|c|c}
\hline \multicolumn{2}{|c|}{ Streptmoycin-producing strains } & Grisein-producing strains & $\begin{array}{c}\text { Pink-pigment } \\
\text { producing strains }\end{array}$ \\
Glucose & - & + & - \\
\hline Glycerol & - & + & + \\
\hline Sucrose & - & + & - \\
\hline Maltose & + & + & - \\
\hline
\end{tabular}

Dulaney has found that streptomycin-producing S. griseus does not grow in the medium with glucose and nitrate and grows in the medium with maltose and nitrate. It conforms to the writer's experiment.

\section{Discussion}

The classification of streptomyces is based upon the microscopical morphological characters, the color of the aerial mycelium and the growth the specific pigment production and various reactions in the various media.

The most important typic characters of $S$. griseus are the straight chain of spherical to oval conidia, no spiral formation, rapid liquefaction of gelatin and coagulated serum. In these points all strains including streptomycin-producing, grisein-producing and pinkpigment-producing strains which were examined by the writer conform to S. griseus. In the classification of streptomyces the pigment production is recognized as one of key characters indicating a special species. However, the pink-pigment-production, though it is a stable character of such a strain, cannot be thought as so important to differenciate the strain from S. griseus. Umezawa and others found that one of these strains produces a little amount of streptomycin, and the writer observed that some of them indicate grisein-like antibacterial spectra around their colonies. Waksman and his coworkers (6) obtained such a strain during the studies of typic S. griseus and found that it produces an antibiotic against gram-positive bacteria. The kinds of antibiotics produced by pink-pigment-producing strains are very various. On the other hand from various strains of typic S. griseus, not only streptomycin and grisein but also the antibiotic against gram-positive bacteria are obtained. Therefore the antibiotic production does not differentiate pink-pigment-producing strains from typic S. griseus. The writer agrees with Waksman's opinion that the pink-pigment-producing strain is am utant or a variant of S. griseus. However, since this pigment production is stable, so this character is worthy for differentiating the types among S. griseus.

The thick growth on potato plugs and the yellow pigment on those media are thought to be a key for S. griseus. However, as the writer indicated, this character can not be always confirmed on all strains. There are 12 streptomycin-producing strains 
which show the typic characters except this point. It suggests that this is not a key character of S. griseus.

After systematic studies Pridham reported the classification of streptomyces on the basis of the utilization of carbohydrates. Enteric bacteria are usually classified on the acid production from various carbohydrates. According to Pridham, the utilization of carbohydrates cannot classify streptomyces by itself alone, but is valuable in assisting the classification. He noticed that S.lavendulae, S. griseus and $S$ antibiotics can be differentiated by their utilization of rhamnose, raffinose and xylose. The writer also found that all strains of $S$. griseus tested use xylose but not raffinose and rhamnose. This character seems to be very important for S. griseus.

Moreover the pink-pigment-producing $S$. griseus is different from the other on their reaction to glycerol, glucose, sucrose and maltose. The streptomycin-producing typic $S$. griseus also shows a specific character on the utilization of these sugars. The results shown in Table 2 are thought to be worthy for differentiating three types of $S$. griseus. The writer thinks that $S$. griseus can be divided into three types owing to their characters of streptomycin production, grisein production, pink-pigment production and the utilization of above four kinds of sugars.

The effect of bacteriophage is generally strain specific. The experiment also indicates that actinophage is also strain specific. Therefore actinophage can not make it possible to divide $S$. griseus into subgroups. Though Waksman has indicated that by testing the sensitivity to actinophage the streptomycin production of each strain is rapidly confirmed, the effect of phage is strain specific and this method should miss some of streptomycinproducing strains. The methods to coniirm the streptomycin production of an individual strain by testing their effect against streptomycin-fast $E$. coli or streptomycin-depent bacteria are superior to the phage method.

The relation of carbohydrates to the kinds of nitrogen sources is important. As Pridham noticed, streptomycin-producing S. griseus consumes glucose in the presence of ammonium sulfate, but as Dulaney (7) and the writer noticed, it does not cosume in the presence of sodium nitrate as the only nitrogen source. On this relation the fact that maltose is consumed with the nitrogen source of nitrate is interesting. Generally the sugar decomposition starts with the phosphorylation. The writer inoculated streptomycin producing strain to the medium containing $0.5 \%$ ammonium sulfate, $0.1 \% \mathrm{~K}_{2} \mathrm{HPO}_{4}, 0.05 \%$ $\mathrm{MgSO}_{4}, 0.05 \% \mathrm{KCl}, 0.001 \% \mathrm{FeSO}_{4}$ and various amounts of nitrate $(0,0.5,1.0,2.0 \%)$ and mesured the inorganic phosphorus in the liquid after various incubation days $(0,1,2,3$, 4, 5 days) by the method described by King (8). In this case the addition of nitrate did not influence on the consumption of phosphor in the liquid. The inorganic phosphorus decreased until about 3 days' incubation and then increased. It suggests that the nitrate does not inhibit the consumption of glucose with ammonium sulfate. When, instead of glucose, maltose is added to the medium, the addition of nitrate promoted the consumption of inorganic phosphorus. It suggests that maltose is consumed with either ammonium sulfate or nitrate as the nitrogen source. Glucose and maltose seem to be consumed through different ways. This agrees with the experiments of Sobotka and others (9) on 
the utilization of glucose and maltose by yeast.

\section{SUMMARY}

According to the descriptions in Bergey's Manual of Determinative Bacteriology 1948, S. griseus can be classified. However the writer could divide this species into three groups as shown in the following:

1. The streptomycin-producing type.

It utilizes maltose, but not glucose, glycerol and sucrose, when the nitrate is added as a nitrogen source.

2. The grisein-producing type.

It utilizes glycerol, glucose, maltose, and sucrose with nitrate as a nitrogen source.

3. The pink-pigment producing type.

It utilizes glycerol but not glucose, sucrose and maltose with nitrate as a nitrogen source.

The yellow-pigment production on the potato was thought not to be a key character for S. griseus. The actinophage was strain specific and could not be used for difierentiating types. All strains of $S$. griseus utilized xylose, but not rhamnose and raffinose.

The utilization of sugars was found to depend upon the kinds of nitrogen sources.

Here the writer should like to express his. sincere appreciation to Dr. H. Umezawa, the Director of the Anibiotic Division of the National Institute of Health of Japan, for his kind direction and valuable advices. Also the writer thanks the officers in General Head Quarters of Allied Forces and Prof. Waksman of giving two strains of S. griseus $\left(R_{\mathbf{4}}-3463, R_{\mathbf{4}}-3475\right)$

\section{REFERENCES}

1) Krainsky, A.: Die Aktinomyceten und ihre Bedeutung in der Natur. Cent. f. Bakt. 41, 662, 1914.

2) Waksman, S. A.: Cultural studies of species of Actinomyces. Soil Sci., 8, 71, 1919.

3) Okami, Y.: Studies on the characters of antibiotic Streptomyces. III. Characters of griserinproducing strains. Jap. Med. J., 2, 203-206, 1949.

4) Umezawa, H., Okami, Y., Kametani, R., Kawahara, A., \& Osato, T.: An observation of actinophage during the streptomycin production in the stainless steel fermenter. J. Antibiotics (Japan), III. Suppl. 22-27, 1950.

5) Pridham, T. G. \& Gottlieb, D.: The utilization of carbon compounds by some actinomycetales as an aid for species determination. J. Bact., 56, 107, 1948.

6) Waksman, S. A., Reilly, H. 'C. \& Johnstone, D. B.: Isolation of streptomycin-producing strains of Streptomyces griseus. J. Bact., 52, 393-397, 1946.

7) Dulaney, D. L.: Observations on Streptomyces griseus. Nitrogen sources for growth and streptomycin production. J. Bact., 56, 305-313, 1948.

8) King, E. J.: The colorimetric determination of phosphorus. Biochem. J., 26, 292, 1932.

9) Sobotka, H. \& Holzman, M.: Direct fermentation of maltose. Biochem. J., 28, 734, 1934. 